\author{
I. J. Popov \\ Engineer, the All-Union Scientific \\ Research Institute of Hydrotechnics \\ named for B. E. Vedeneev \\ Leningrad, U.S.S.R.
}

\title{
INTRODUCTION
}

Within the last few years the Soviet hydraulic engineers have beer making continuous efforts to avoid use of concrete slabs and blocks and stone riprap as protective cover of upstream slopes of earth dams and reservoir shores against the disrupting effects of waves generated by the action of wind upon the water surface.

Their efforts have been aimed at finding the cheaper procedure. Of all the possible ways of slope and shore protection, an engineering measure, the idea of which consists in distributing the wave energy dissipation over a considerably large portion of a sufficiently gentle slope, should be given a special attention. This measure makes it possible to substantially relieve the protective cover and in some cases to leave the slope uncovered. The possibility of unlined slopes, stable enough agains wave action is proved out by the experience of reservoir operation. Shores and underwater slopes of artificial lakes composed of non-cohesiv soils are usually subject to considerable disintegration due to wave action The process of disintegration which goes on rather fast at the initial stage of lake existance, slows down with the formation of a flat lake-side shallow, whereon dissipation of wave energy takes place. At a certain stage of development the underwater slope assumes such dimensions and outlines which enable it to dissipate the whole of the wave energy and practically to protect shores from further destruction. The profile of the slope at which it will permanently stand underwater is referred to as the "profile of equilibrium" or "dynamically stable profile". The term "equilibrium" in this case doesn't imply absolute immovability of the material acted on by waves, but stands for such a movable state at which particles of the soil are making oscillatory movements round some middle position without the resultant movement neither towards nor 


\section{EXPERIMENTAL RESEARCH IN FORMATION BY WAVES OF STABLE PROFILES OF UPSTREAM FACES OF EARTH DAMS AND RESERVOIR SHORES}

off shore.

The problem, thus, is reduced to reproducing on the submerged slope of a dam during construction or on shores of a future reservoir the rellef analagous to that of the bottoms of long-term reservoirs or artificial lakes (ponds) and seas.

Dimensions of waves, the direction in which the wave rides up the shore or structure, limits of reservoir water level fluctuations and size of soil particles are controlling factors determining outlines of the profile of equilibrium.

In 1957-58 the Hydraulic Laboratory of the All-Union Scientific Research Institute of Hydrotechnics named for B. E. Vedeneev initiated a test program on wave effect on the upstream slopes of earth dams and on reservoir shores.

The first series of tests have been carried out to study the influence of the two above-mentioned factors, that is: dimensions of waves (height and length) and size of particles of non-cohesive soil on the form of the profile of equilibrium.

The purpose of the test program was to set up the design relations by means of which it would be possible at given wave dimensions and grain-size distribution in an earth structure to determine the outlines and dimensions of the underwater slope which provide its stability without lining, the wave ride-up being frontal and the level of still water in a reservoir being constant.

The following notations are used in this paper

$$
\begin{aligned}
\mathrm{h} & =\text { the height of the wave from trough to crest } \\
\lambda & =\text { the length of the wave } \\
\mathrm{d} & =\text { the diameter of the soil grains } \\
\nu & =\text { the coefficient of kinematic viscosity of water } \\
\mathrm{g} & =\text { the acceleration of gravity }
\end{aligned}
$$

Symbols " $\mathrm{m}$ " and " $\mathrm{p}$ " indicate that the above values should be referred to model and prototype respectively.

$\alpha_{\ell}=$ the geometrical scale coefficient for values of linear dimensions

$$
\left(a_{\ell}=\frac{h_{p}}{h_{m}}=\frac{\lambda p}{\lambda_{m}}=\frac{d p}{d_{m}}\right)
$$


I. INVESTIGATIONAL METHODS. TESTING PROCEDURE AND BRIEF DESCRIPTION OF EXPERIMENTAL SET-UPS

The stability of particles of non-cohesive soils on the slope subject to wave action is determined, apart from gravity, by the following principal forces :

1. Forces resulting from streamlining of soil particles by the liquid with variable in time, value and direction bottom velocities caused by wave action above the slope surface.

2. Variable in value and direction percolation forces normal to the surface of the slope acting on a particle out from the porous medium of the slope.

The shallow-water-wave-over-an-inclined bottom theory does not afford opportunities to set up the functional relationships permitting to determine by way of calculations the velocity and pressure fields in a bottom layer. In connection with this it should be noted that, at the time being, it seems impossible to obtain the equation of equilibrium of soil particles on the surface of pervious slope and to determine the gradients corresponding to the stable state of the latter. This largely explains for experimental way of studies.

The first and foremost problem arising from consideration of different testing procedures is the problem how the values obtained during tests should be adapted to prototype. If we were sure beforehand that the forces determining the stability of soils on the slope obey scaling-up according to the law of gravitational similarity (Froude's law) it would be enough to obtain in laboratory conditions the stable profiles of slopes for a number of wave height-to-grain diameter ratios $a_{1}=\frac{h_{1 m}}{d m}, a_{2}=\frac{h_{2 m}}{d_{m}}$ etc, and using geometrical scale coefficient to adopt them to prototype for the same values of $a_{\ell}$. It goes without say ing that the grain diameter would be scaled-up in accordance with the geometrical scale coefficient of the model $\left(d_{p}=a_{\ell} \cdot d_{m}\right)$.

However, of all the forces acting on soil particles on the surface of the slope, only external wave pressure probably obeys Froude's law. Scaling -up of the bottom velocities by this law is strongly doubted, and as to seepage phenomena associated with reservoir roughness they can hardly obey, due to their nature, the law of gravitational scaling-up.

Taking into consideration the said above, a conclusion could be easily drawn that the geometrical scaling-up of grain-size and wave dimensions does not provide the same geometrical similarity of stable 


\section{EXPERIMENTAL RESEARCH IN FORMATION BY WAVES OF STABLE PROFILES OF UPSTREAM FACES OF EARTH DAMS AND RESERVOIR SHORES}

profiles formed by waves (this is referred at least to those cases when model tests are carried out on a relatively small scale).

The absence of the theory of scaling-up the erosion and deposits of non-cohesive soils due to wave action necessitated that scale series of tests should be carried out in laboratory conditions, $i . e$. such tests when a phenomenon under investigation was reproduced on different geometrical scales.

Experimental research consisted of three testing series corresponding to three grain-sizes respectively: $d_{60}=2 \mathrm{~mm} x$ ) (1st series), $\mathrm{d}_{60}=3.5 \mathrm{~mm}$ (2nd series) and $\mathrm{d} 60=6.0 \mathrm{~mm}$ (3d series), the coefficients of non-uniformity being equal to $K=\frac{d 60}{d 10}=1.2 \div 1.8, \quad .63$ tests were made on sands of the above-mentioned grain-size, wave heights being from 5 to $40 \mathrm{~cm}$ and steepness $E=\frac{h}{1}=\frac{1}{10}, \frac{1}{12}, \frac{1}{15}$ and $\frac{1}{20}$. The tests were carried out in two glass flumes: one $14 \mathrm{~m}$ long, $0.7 \mathrm{~m}$ wide, and $1.3 \mathrm{~m}$ deep, the other $30.5 \mathrm{~m}$ long, $0.65 \mathrm{~m}$ wide and $2.0 \mathrm{~m}$ deep. Both flumes were provided with pusher-type wave generators .

\section{THE RESULTS OF THE EXPERIMENTS}

Numerous successive photographs of the profile of the slope in different stages of forming by waves, also measurements of bottom velocities by means of specially designed measuring calls make it possible to characterize the process in the following way.

Formation by waves of a stable profile is the continuous damping process of erosion of the upper part of the slope and of accumulation of the eroded material in the lower part. The stable slopes have peculiar curved outlines with four characteristic zones (Fig. 1, heavy line 1-2$3-4-5)$ being as follows:

1. Above-water zone limited from above by point 1 , the uppermost point of wave ride up on the slope, and from below, by point 2 , the point of intersection of the profile of the slope with the still water level.

2. Below point 2 there is a comparatively flat underwater zone 2-3 elongated up to the bottom of the hollow.

3. Immediately after the hollow there is an underwater roller of which the uppermost point 4 may be assumed for the extreme right boundary of the third zone 3-4.

4. Finally there is the fourth zone ending with point 5 which is

$\mathrm{x}) \mathrm{d}_{60}$ is the grain diameter; number 60 indicates that the content of finer grains in a sample is $60 \%$ by weight. 
the lower limit of the stable slope formed by wave action. Below this point the profile of the slope is represented by a straight line inclined towards the horizon, the angle of inclination being that of the natural slope of soil in water.

The above outlines of the stable slope was characteristic for the whole test program with wave dimensions being as $\mathrm{h}_{\mathrm{m}}=5$ to $40 \mathrm{~cm}$ and

$\lambda_{m}=50$ to $600 \mathrm{~cm}$ and grain-size of soils being as $\mathrm{d}_{60}=2.0 ; 3.5$ and $6.0 \mathrm{~mm}$. Changes in wave dimensions and grain-size of soils leads only to changes in dimensions of the above-mentioned zones, of their slopes, etc., but does not lead to substantial difference in forms of slopes taken as a whole.

At the initial stage of the process of formation by waves of the stable profile erosion of the upper part of the slope is going on rather fast with point 1 and 2 moving continuously in the direction of the structul

The zone 2-3 in its upper part flattens. The lower limit of wave forming action - point 5 moves in the direction of the reservoir and slowly sinks below the still water level (SWL). As to the hollow and the underwater roller, these two elements of the profile formed at the very start of testing remain practically unchanged as far as their position and form are concerned.

Since the curved form of the profile of unlined slopes is not convenient both from the standpoint of calculations and mainly from the standpoint of construction works, we think it necessary to schematize this form, presenting the design scheme in the form of cut-off lines averaging the curved portions of the profile obtained in experiments. (Fig. 2, broken line ABCDE).

The relationship between dimensions of the stable profile on factors determining these dimensions may be written as

$$
\ell=f(d, h, \lambda, g, \nu)
$$

where

$$
\begin{aligned}
& \ell=\begin{array}{l}
\text { certain linear characteristics of the profile } \\
\text { (length, depth, etc.) }
\end{array} \\
& \mathrm{d} \quad=\text { grain diameter of sand } \\
& \mathrm{h} \quad=\text { wave height }
\end{aligned}
$$




\section{EXPERIMENTAL RESEARCH IN FORMATION BY WAVES OF STABLE PROFILES OF UPSTREAM FACES OF EARTH DAMS AND RESERVOIR SHORES}

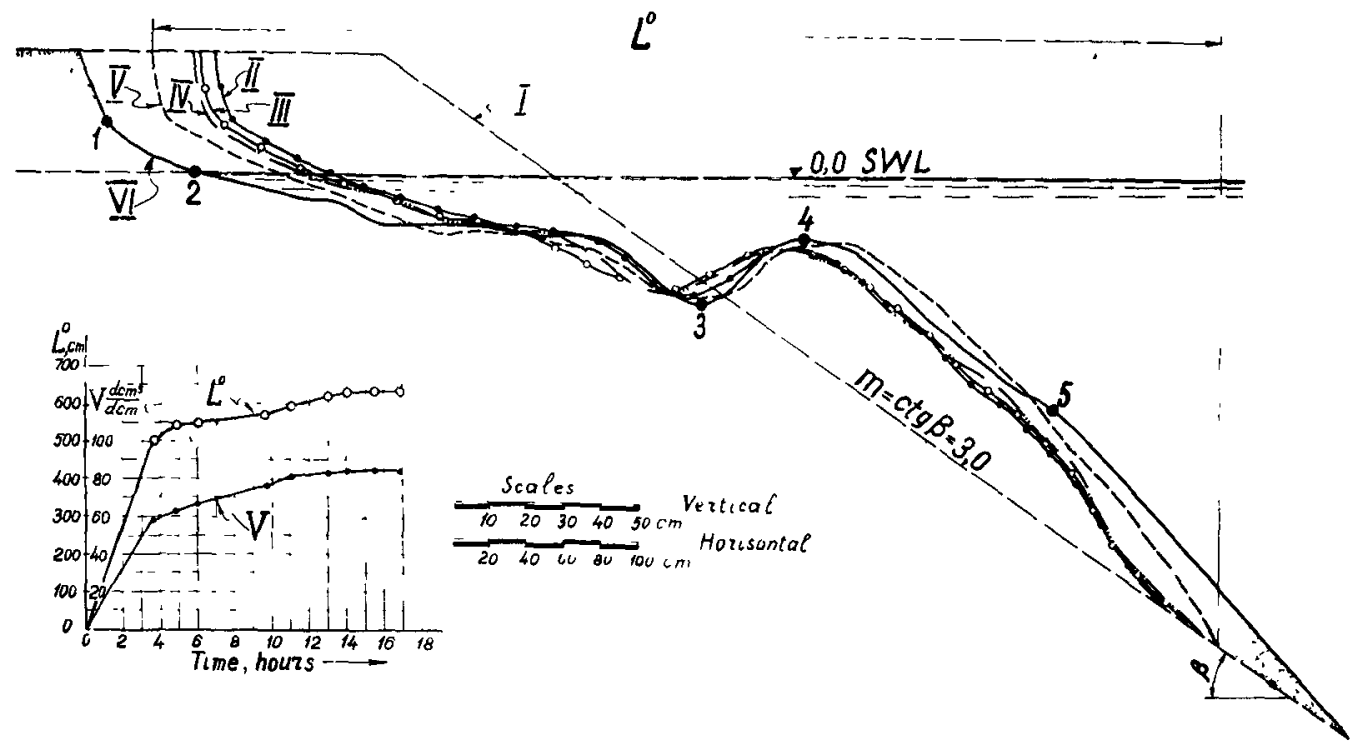

Fig. 1. Different stages of the process of formation by waves of a stable profile of the slope. Gravel with the grain diameter $\alpha_{60}=6 \mathrm{~mm}$. Wave parameters: $\mathrm{b}=30 \mathrm{~cm} ; \lambda=450 \mathrm{~cm}$; $\mathrm{T}=1.73 \mathrm{sec}$.

$$
\begin{aligned}
& \text { I - orlginal slope. } \\
& \text { II - profile of the slope after } 3.6 \text { hours. } \\
& \text { III - " " " " " " } 4.8 \text { hours. } \\
& \text { IV - " " " " } 6.0 \text { hours. } \\
& \text { V - " " " " " " } 9.6 \text { hours. } \\
& \text { VI - " " " " } 16.8 \text { hours. } \\
& I^{\circ} \text { - slope length, cm. } \\
& \mathrm{V} \text { - volume of erosion, } \mathrm{dcm}^{3} / \mathrm{dcm}
\end{aligned}
$$

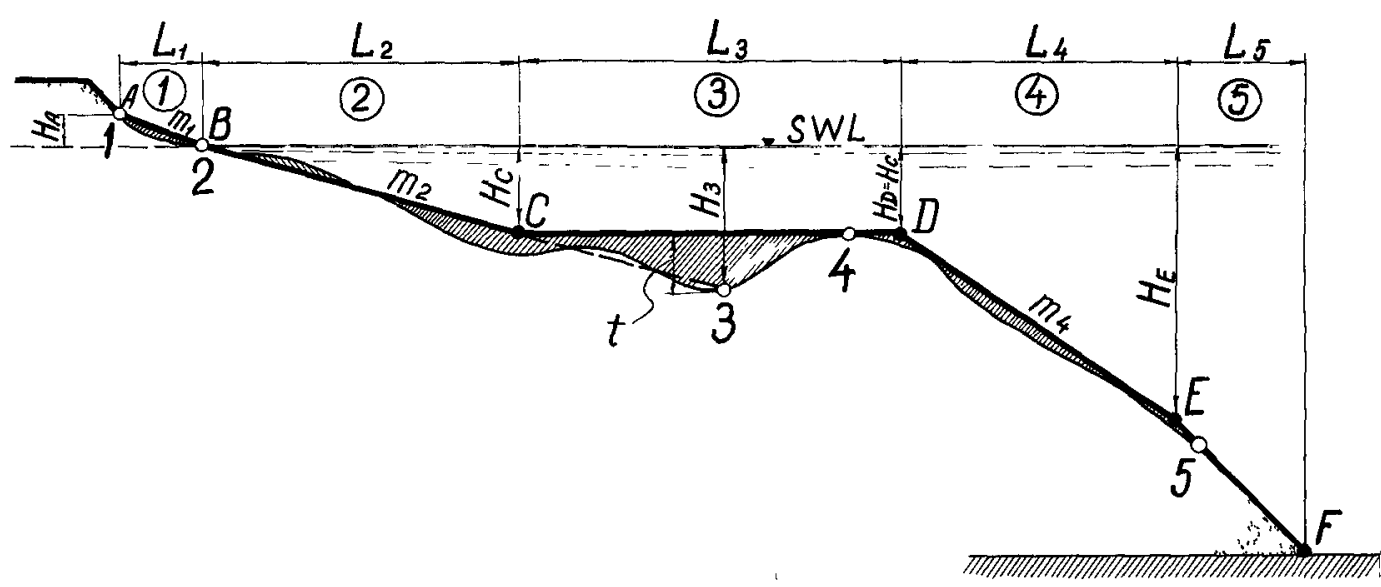

Fig. 2. Design scheme for construction of the profile of the stable unlined slope. Design values:

$$
H_{A} ; \quad M_{1}=\frac{L_{I}}{H_{A}} ; \quad M_{2}=\frac{I_{2}}{H_{C}} ; \quad H_{287}\left(H_{D}\right) ; \quad I_{3} ; \quad M_{4}=\frac{I_{4}}{H_{E}-H_{D}} ; \quad H_{E}
$$




\section{COASTAL ENGINEERING}
$\lambda=$ wave length
$g$ = acceleration of gravity
$\nu=$ coefficient of kinematic viscosity of water

Using methods of the theory of dimensions we have set up the following system of dimensionless parameters which determine the phenomenon under investigation and satisfy the requirements of the theory of similarity: $\frac{l}{h}, \frac{h}{d}, \frac{h}{\lambda}$ and $\sqrt{\frac{d \cdot d}{\nu}}$ In connection with this equation (1-A) may be re-written in the following form:

$$
\frac{l}{h}=\psi\left(\frac{h}{d}, \frac{h}{\lambda}, \frac{\sqrt{g d} \cdot d}{\nu}\right)
$$

As a result of the analysis of the experimental data the following empiric relationships for the determination of the geometrical elements of the profile of equilibrium are obtained:

1. Relative height of the wave run-up on the slope at

$$
\begin{gathered}
10<\frac{\mathrm{h}}{\mathrm{d}} \leq 100 \\
\frac{\mathrm{H}_{\mathrm{A}}}{\mathrm{h}}=5.65 \frac{\mathrm{d}}{\mathrm{h}}-4.3 \frac{\mathrm{h}}{\lambda}+0.58
\end{gathered}
$$

and at $\frac{h}{d}>100$

$$
\frac{\mathrm{H}_{\mathrm{A}}}{\mathrm{h}}=0.63-4.3 \frac{\mathrm{h}}{\lambda}
$$

2. Coefficient of slope (cotangent of angle of inclination of the slope towards the horizon) $M_{1}$, elongation $A B$

$$
\text { at } \begin{aligned}
200 & <\frac{\sqrt{g d} \cdot d}{\nu} \leq 1200 \\
m_{1} & =\left(2-5 \cdot 10^{-4} \frac{\sqrt{g d} \cdot d}{\nu}\right)\left(\frac{h}{d}\right)^{1 / 4} \ldots .
\end{aligned}
$$


EXPERIMENTAL RESEARCH IN FORMATION BY WAVES OF STABLE PROFILES

OF UPSTREAM FACES OF EARTH DAMS AND RESERVOIR SHORES

and at $\frac{\sqrt{\mathrm{gd}} \cdot \mathrm{d}}{\nu}>1200$

$$
M_{1}=1,3\left(\frac{h}{d}\right)^{1 / 4}
$$

3. Coefficient of slope $\mathrm{M}_{2}$, elongation $\mathrm{BC}$.

$$
M_{2}=\left(2.9-10 \frac{h}{\lambda}\right)\left(\frac{h}{d}\right)^{1 / 3} \ldots . .
$$

level.

4. Deepening of the horizontal elongation $\mathrm{CD}$ beIow the water

$$
\mathrm{H}_{\mathrm{C}}=\mathrm{H}_{\mathrm{D}}=0.6 \mathrm{~h}
$$

5. Relative length $\mathrm{L}_{3}$, elongation $C D$.

$$
\frac{L_{3}}{h}=\left(0.6-3 \frac{h}{\lambda}\right)\left(\frac{h}{d}\right)^{1 / 3}
$$

6. Coefficient of slope $\mathrm{M}_{4}$, elongation $\mathrm{DE}$.

$$
\begin{aligned}
& \text { at } \frac{\mathrm{h}}{\mathrm{d}}>40 \\
& \mathrm{M}_{4}=\frac{460 \cdot \nu}{\sqrt{\mathrm{gd} \cdot \mathrm{d}}}+2.1
\end{aligned}
$$

and at $\frac{h}{d}<40$

$$
\mathrm{M}_{4}=\mathrm{K}\left(\frac{460 \cdot \nu}{\sqrt{\mathrm{gd} \cdot \mathrm{d}}}+2, .1\right)
$$

where $K$ should be assumed according to the following Table: 
COASTAL ENGINEERING

\begin{tabular}{|l|l|l|l|l|l|l}
\hline$\frac{h}{\mathrm{~d}}$ & 10 & 15 & 20 & 25 & 30 & 40 \\
\hline $\mathrm{K}$ & 1.7 & 1.5 & 1.3 & 1.2 & 1.1 & 1.0 \\
\hline
\end{tabular}

7. Relative depth above point $E$

$$
\frac{H_{E}}{h}=\left[\frac{400 \cdot \nu}{\sqrt{g d \cdot d}}+0.55-\left(\frac{1800 \cdot \nu}{\sqrt{g d \cdot d}}+2.3\right) \frac{h}{\lambda}\right]\left(\frac{h}{d}\right)^{n}
$$

where

$$
\mathrm{n}=0.27-\frac{35.9 \cdot \nu}{\sqrt{\mathrm{gd} \cdot} \mathrm{d}}
$$

In the above formulae for the design diameter of noncohesive soils was assumed the grain-size of which finer particles content is $60 \%$ of the material by weight.

When structures are being built of fine-grained sands it seems more economic to cover the upstream slope by the protective layer of coarse-grained materials according to the scheme, being as shown in Fig. 3. This will considerably reduce the volume of earth works. The following empiric formula is obtained to determine the thickness of the protective layer.

$$
\delta=K \cdot 0.02\left(\frac{h}{d}\right)^{2 / 3}
$$

where $K$ is the safety factor which should be assumed as being equal to 2.0 at $\frac{h}{d} \leq 70$ and to 1.5 at $\frac{h}{d}>70$.

The above formulae may be used in the design and construction of gentle slopes composed of soils with the grain diameter $d=2.0 \mathrm{~mm}$ subject to wave action, the wave height being up to $1.5 \mathrm{~m}$.

It is our opinion that the results of investigations obtained herein 
EXPERIMENTAL RESEARCH IN FORMATION BY WAVES OF STABLE PROFILES OF UPSTREAM FACES OF EARTH DAMS AND RESERVOIR SHORES

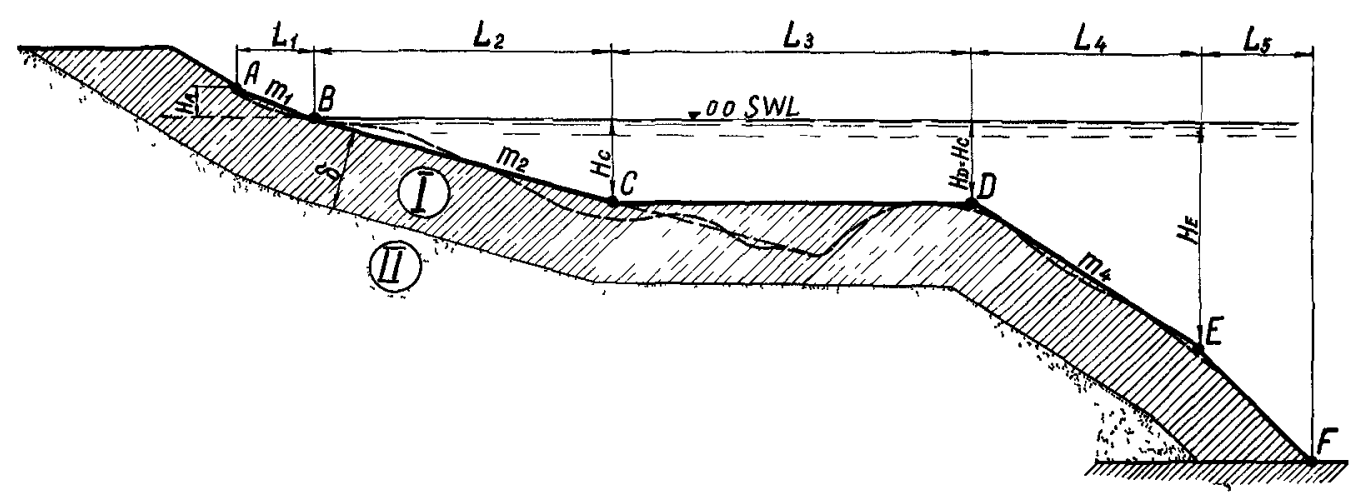

Fig. 3. Scheme of the slope of an earth structure with protective cover on 1 t.

I - protective layer made of coarse sand or gravel.

II - hydraulically filled structure built of sand.

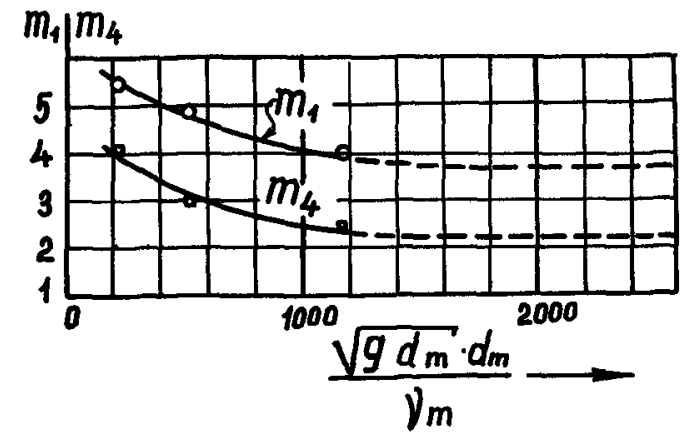

F18. 4

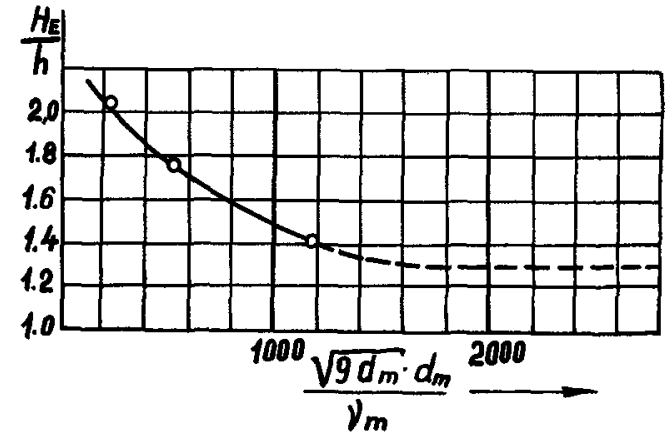

Fig. 5

F1g. 4 Variation of coefficients of slope $M_{1}$ and $M_{4}$ dependent on the value of $\frac{\sqrt{\mathrm{g} \cdot \mathrm{d}_{\mathrm{m}}} \cdot d_{\mathrm{m}}}{v_{\mathrm{m}}}$

$\frac{h}{\mathrm{~h}}=66.7 ; \quad v=0.0124 \frac{\mathrm{cm}^{2}}{\mathrm{sec}}$

Fig. 5 Relationshlp between relative depth (the lower limit of wave forming action) $\frac{H_{E}}{h}$ and the value of $\frac{\sqrt{g d_{m}} \cdot d_{m}}{v_{m}}$ $\frac{\mathrm{h}}{\mathrm{d}}=66.7 ; \quad v=0.0124 \frac{\mathrm{cm}^{2}}{\mathrm{sec}}$ 
are of some interest from the point of view of predicting the volume of work made by waves on natural shores of newly built reservoirs.

\section{SOME CONSIDERATIONS ON SCALING-UP EROSION AND DEPOSITION OF NON-COHESIVE SOILS DUE TO WAVE ACTION}

The analysis of the results obtained from the point of view of scaling-up the elements of the profile, the geometrical scale of the model with geometrically scaled grain-size and wave dimensions being taken account for, made it possible to draw the following conclusions.

Elements of the stable profile according to the assumed design scheme (Fig . 2) may be divided into two groups being as follows:

1. The first group comprises values $\mathrm{H}_{\mathrm{A}}, \mathrm{M}_{2}, \mathrm{H}_{\mathrm{C}}, \mathrm{L}_{3}$ and $\delta$ determined by relations $1,2,4,5,6,7$ and 11 involving besides constant coefficients relative dimensionless values $\frac{h}{f}$ and $h$. Thus in meeting requirements $\frac{h_{m}}{d_{m}}=\frac{h_{p}}{d p} \ldots$ (12) and $\frac{h_{n}}{\lambda_{m}}=\frac{h_{p}}{\lambda_{p}} \cdot$. (13) and also in maintaining the boundary conditions the $\lambda_{m}$ entioned above values may be scaled-up to the prototype by way of multiplying the corresponding values obtained in the test by geometrical scale coefficient.

Such scaling-up is undoubtedly justifiable if sand with the grain diameter $d_{m} \geq 2$. Omm is used on the model as eroded material and the requirement $\frac{h}{d}=20$ is met.

2. The second group comprises values $M_{1}, M_{1} 4$ and $H_{E}$ for which as it may be seen from relations $3,8,9$ and 10 , geometrical similarity model and prototype might have been provided if an additional requirement

$$
\frac{\sqrt{g d_{m}} \cdot d_{m}}{\nu_{m}}=\frac{\sqrt{g d_{p}} d p}{\nu_{p}}
$$

besides conditions 12 and 13 was met.

If it was not, geometrical scaling-up of values $M_{1}, M_{4}$ and $H_{E}$ is not guaranteed.

Moreover, at $\frac{\sqrt{g d_{m}} d_{m}}{\nu_{m}} \leq 1000$ it may lead to substantial error This circumstance is clearly illustrated by the diagrams shown in Figs . and $5^{x}$ ). These diagrams show the dependency of values $M_{1}, M_{4}$ and $\mathrm{H}_{\mathrm{E}}$

x) In Figs. 4 and 5 the curves shown by dotted lines have been plotted according to the corresponding empirical relations 3,9 and 10 . 


\section{EXPERIMENTAL RESEARCH IN FORMATION BY WAVES OF STABLE PROFILES OF UPSTREAM FACES OF EARTH DAMS AND RESERVOIR SHORES}
on values of $\frac{\sqrt{g d_{m}} \cdot d_{m}}{\nu_{m}} \quad$ for one particular case: $\frac{h}{\lambda}=10$ and $\underline{h}=66.7$ (ratio between maximum wave height $40 \mathrm{~cm}$ and maxjmum grain- $\bar{g}_{\text {ize }} d_{m}=6.0 m m$ i.e. $\left.\frac{h_{m \text { max }}}{d_{\text {max }}}=\frac{400}{6}=66.7\right)$. With $\frac{\sqrt{g_{0} d_{m}}}{\nu_{m}}=\geq 1000$ i.e. with using sand of which the grain diameter $d_{m}=5 \mathrm{~mm}$ values $M_{1}$, $M_{4}$ and $\mathrm{H}_{\mathrm{E}}$ can be practically scaled up in accordance with geometrical scale of the model (the error being not more than $15 \%$ toward exaggera - tion).

It should be noted that supposition of possibility of scaling-up all elements of the profile is the basis of many investigational works associated with studying the disruptive effects of waves on shores and bottom reservoirs.

The preliminary results given in this paragraph show that such scaling is far from being always justifiable. 